\title{
Histopathology of optic nerve pit-associated maculopathy
}

This article was published in the following Dove Press journal:

Clinical Ophthalmology

24 July 2012

Number of times this article has been viewed

\section{John B Christoforidis William Terrell \\ Frederick H Davidorf}

College of Medicine, The Ohio State University, Columbus, $\mathrm{OH}$, USA
Correspondence: John Christoforidis Havener Eye Institute-Retina Division, The Ohio State University,

915 Olentangy River Rd,

Columbus, $\mathrm{OH} 43210$, USA

$\mathrm{Tel}+\mathrm{I} 614293804 \mid$

Fax + I 6146522610

Email john.christoforidis@osumc.edu
Purpose: To describe the histopathologic findings of an eye bank specimen containing an optic nerve pit with associated serous elevation of the macula and cavernous atrophy of the optic nerve.

Methods: An eye bank specimen found to have an optic nerve pit with serous elevation of the macula was grossly examined and photographed. The globe was processed for both light and scanning electron microscopy.

Results: The scanning electron microscopic study of this eye with an optic nerve pit revealed holes in the diaphanous membrane overlying the nerve at the edge of the optic pit. Serial histopathology sections revealed a connection between the holes overlying the optic pit and the subretinal space via a schisis-like cavity in the retina.

Conclusion: The discovery of an optic nerve pit with coexisting serous detachment of the macula in an eye bank eye and subsequent pathological evaluation provides support for current theories into the mechanism of the visual loss in this condition. Our finding supports syneretic vitreous to be the source of the subretinal fluid.

Keywords: optic nerve pit, light microscopy, electron microscopy, retinal detachment

\section{Introduction}

Optic nerve pits are a rare deformity of the optic nerve head originally described by Wiethe in $1882 .^{1}$ These congenital excavations of the optic nerve head appear as localized grey-white to black pits that do not involve the margin of the disc. Optic nerve pits are most commonly located at the temporal side of the disc; however, additional locations within the disc have been described. ${ }^{2}$ They are typically less than one half the width of the disc in size and vary in depth from one to several diopters. ${ }^{3}$ Optic nerve pits have a prevalence of 1 in 11,000 patients as estimated by Reis in 1908 , and they occur almost equally in men and women. ${ }^{4}$ Clinically, optic disc pits are most often asymptomatic. Excluding enlarged blind spots, about $60 \%$ of eyes with optic pits still have visual field deficits by perimetry. ${ }^{5}$ Optic pits most often become symptomatic when they are complicated by localized serous macular detachment. An association between temporally located optic disc pits and serous maculopathy was originally proposed by Reis and furthered by Peterson in $1958 .{ }^{6}$ Serous macular detachment and subsequent visual sequela typically develop in adulthood in approximately $25 \%$ to $75 \%$ of eyes with optic nerve pits. ${ }^{2,6-8}$ Interestingly, optic nerve pits that are located centrally have not been associated with serous maculopathy. ${ }^{9}$ Due to the overall poor visual prognosis of optic pit-associated maculopathy, a complete understanding into the source of the subretinal fluid and the mechanism of macular detachment is essential. 
The pathophysiology of optic pit-associated maculopathy has been debated. Central to the debate is the source of subretinal fluid and the pathway by which it arrives at this location. The two leading hypotheses posit that the source of the subretinal fluid is either the vitreous cavity or the subarachnoid space. At present, few histopathological studies have correlated what has been observed clinically. Previous histopathological studies investigating optic disc pits have utilized standard light microscopy (LM). ${ }^{6,9,10}$ Optical coherence tomography (OCT) has provided significant insight into the mechanism by which optic disc pit-associated maculopathy occurs. ${ }^{11-19}$ This paper presents a histological analysis of an eye bank specimen with optic disc pit-associated maculopathy utilizing light microscopy and scanning electron microscopy (SEM). Our examination of this eye specimen gives further histological insight into the mechanism of optic pit-associated maculopathy.

\section{Materials and methods}

The eye bank specimen was that of a right eye obtained by the Central Ohio Lions Eye Bank 3 hours postmortem. It was from a 79-year-old white male with a known previous history of serous detachment of the macula who died of myocardial infarction. The eye was opened with a razor blade at the equator and examined with a dissecting microscope. An optic nerve pit with serous detachment of the macula was identified, as was an area of chorioretinal atrophy superior to the nerve. Photographs were taken of the gross specimen with a Canon AE-1 camera.

The eye was prefixed for three hours in P-G solution $(2 \%$ paraformaldehyde, $2.5 \%$ glutaraldehyde) in a $0.1 \mathrm{M}$ phosphate buffer. Two specimens were obtained by sectioning through the inferior border of the optic nerve pit. The superior section was prepared for SEM, while the inferior section was prepared for LM. The SEM sample was washed with a buffer solution and then postfixed for 1 hour in a buffered $1 \% \mathrm{OsO}_{4}$ solution. Tissue blocks were dehydrated in a graded ethanol series, and the dehydrated samples were then critical point dried in a Tousimis 601 Samdri (Tousimis, Rockville, MD). The dried blocks were mounted to Kent-Cambridge-type stubs (13 mm) with Avery Spot-O-Glue (ElectronMicroscopy Sciences catalog \#76700, Hatfield, PA) and coated with $100 \AA$ gold palladium in a Polaron SEM coater E5100 (Quorum Technologies, East Sussex, UK). A Hitachi S570 scanning electron microscope (Hitachi, Tokyo, Japan) was used to view samples for SEM. Routine embedding and sectioning techniques were used for LM. The sample was fixed in P-G solution, dehydrated, infiltrated, and embedded in paraffin and sectioned at 6 microns. Routine hematoxylin and eosin staining was done, and the specimen was examined with a Zeiss Photomicroscope 3 (Carl Zeiss Microimaging, Thornwood, NY).

\section{Results}

The photo of the specimen (Figure 1) provides an overall view of the fundus revealing serous elevation of the macula extending to the edge of the optic nerve. The optic nerve pit is seen in the infratemporal quadrant of the disc (arrow) with chorioretinal atrophy superior to the optic nerve. Figure 2A and B define the surface structure of the optic pit using SEM. There are multiple irregularly shaped defects in the membrane overlying the optic pit. Most of the holes are ovals of varying sizes, many with septae. They seem to be of varying depths with the deepest located on the temporal margin of the pit (Figure 2B). There were no visible overlying vitreous attachments in this specimen.

The LM section (Figure 3A and B) is located just inferior to the SEM section described above, and demonstrates schisis within the neurosensory retina. Serial sections reveal a connection between the retinoschisis and the subretinal space (Figure 3C and D). Extensive cavernous atrophy of the optic nerve is seen in Figure 3B (large arrow) with obliteration of the lamina cribrosa. The subarachnoid space is surrounded by an intact vaginal sheath, and meningeal cells can be seen within the subarachnoid space (arrow).

Figure $3 \mathrm{C}$ and $\mathrm{D}$ are serial sections demonstrating the connection between the optic nerve pit and the subretinal space (see diagram, Figure 4). Figure 3C reveals a schisis-like cavity in the inner retina and, further temporally, Figure 3D shows an opening into the subretinal space with loss of normal retinal architecture in this area.

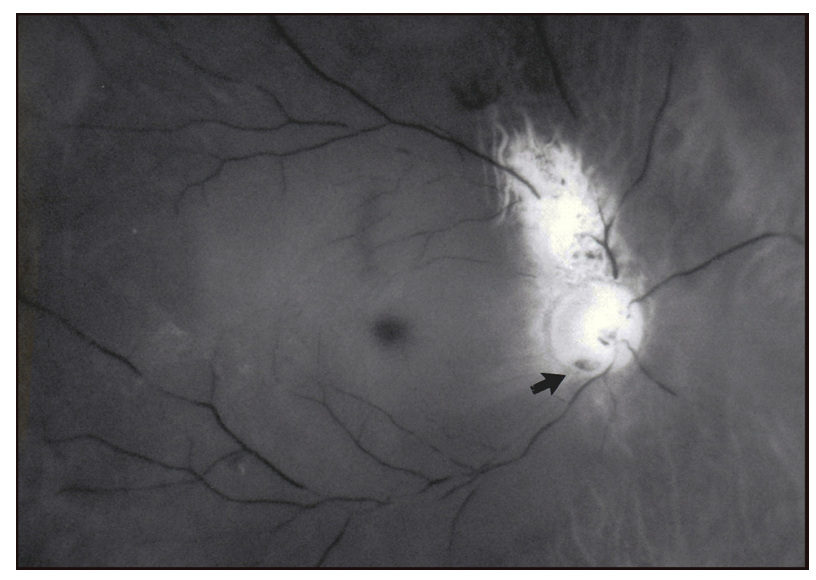

Figure I Fundus photo with a temporally located optic disc pit (arrow) and associated macular detachment. There is chorioretinal atrophy superior to the nerve. 


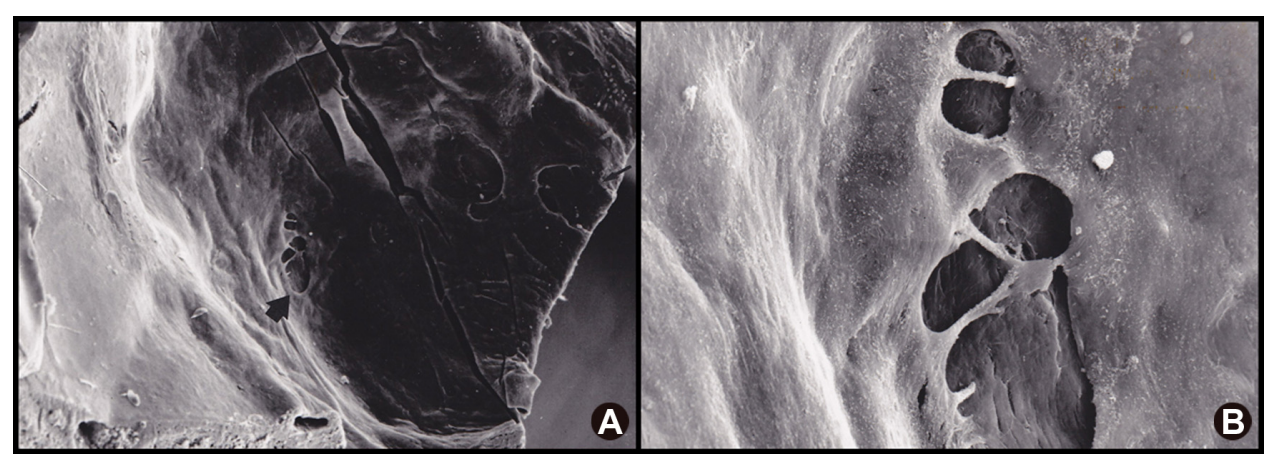

Figure 2 SEM of the optic disc pit with defects in the overlying diaphanous membrane. (A) SEM of the optic disc pit with defects in the overlying diaphanous membrane (arrows). (B) higher magnification allows visualization of the base of the optic pit through these membranous defects.

Abbreviation: SEM, scanning electron microscope.

Figure 5A and B are SEM photomicrographs of the region just temporal to the optic nerve pit. The prominent feature of Figure $5 \mathrm{~A}$ is the cavernous atrophy of the optic nerve with large cystic spaces between the glial septae. The region corresponding to the schisis cavity in the inner sensory retina is located at the top of the photomicrograph (arrow). Figure $5 \mathrm{~B}$ is the same area that has been magnified, revealing extensive atrophy of the inner retinal layers.

\section{Discussion}

The pathogenesis of optic disc pit-associated maculopathy has long been debated. In 1988, Lincoff et al reported
15 eyes with optic disc pit maculopathy utilizing stereoscopic imaging. They proposed a mechanism of localized macular detachment whereby fluid from the optic nerve pit causes an initial schisis-like separation of the retinal nerve fiber layer. An outer retinal lamellar hole then allows for fluid from the inner retinal schisis to gain access to the subretinal space resulting in a serous macular detachment. ${ }^{20}$ To the author's awareness, no histological studies have been published since that time to support their theory. Initial OCT analysis by Krivoy $^{11}$ and Rutledge ${ }^{12}$ lends support to the concept of a bilaminar retinal morphology with initial inner layer schisis and a secondary outer layer detachment.

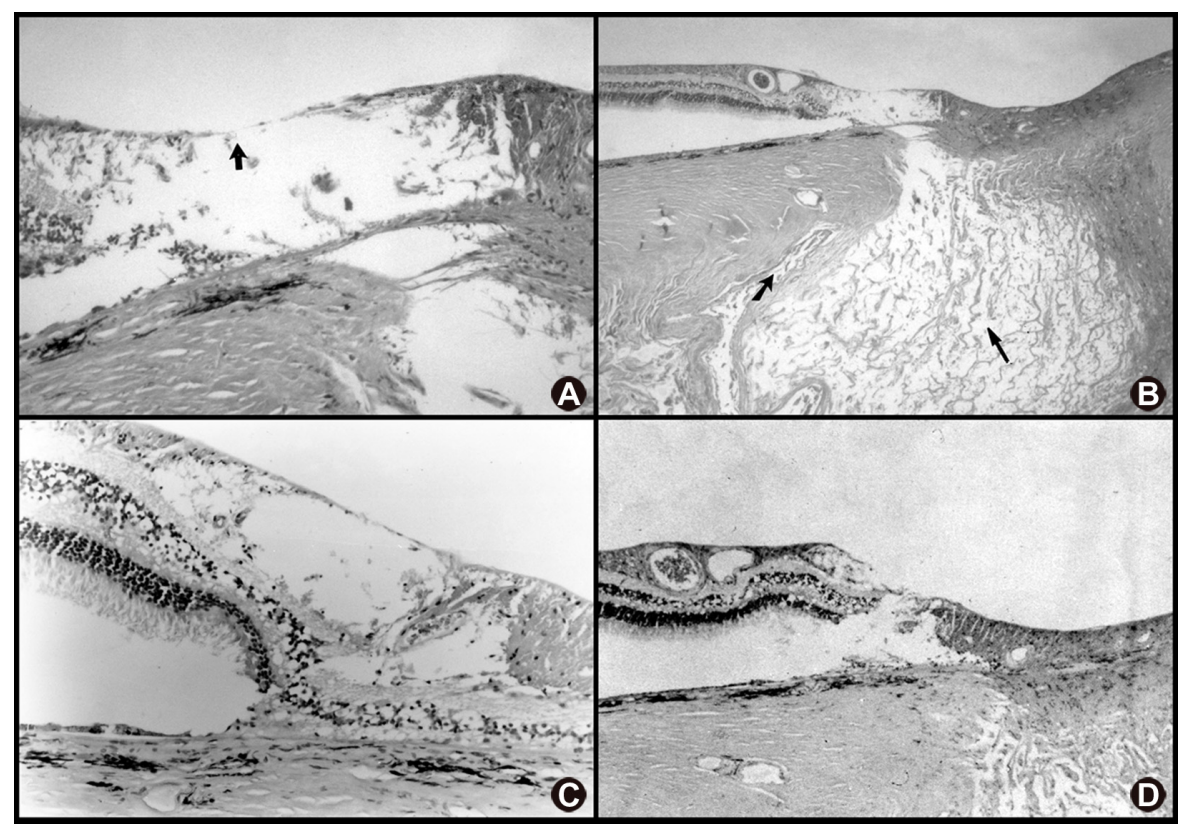

Figure 3 Serial sections through the optic disc pit and adjacent retina. (A) note the schisis cavity and atrophy of the temporal retina adjacent to the optic disc. In this specimen, only ILM remained as a roof of the cavity (arrow). (B) unique to this specimen is extensive cavernous atrophy of the optic nerve (long arrow). Note the intact subarachnoid space (short arrow) without communication to the subretinal space in this section. (C) retinal atrophy has created a schisis cavity adjacent to the optic pit. (D) a lamellar defect below the schisis cavity has resulted in a communication into the subretinal space.

Abbreviation: ILM, internal limiting membrane. 


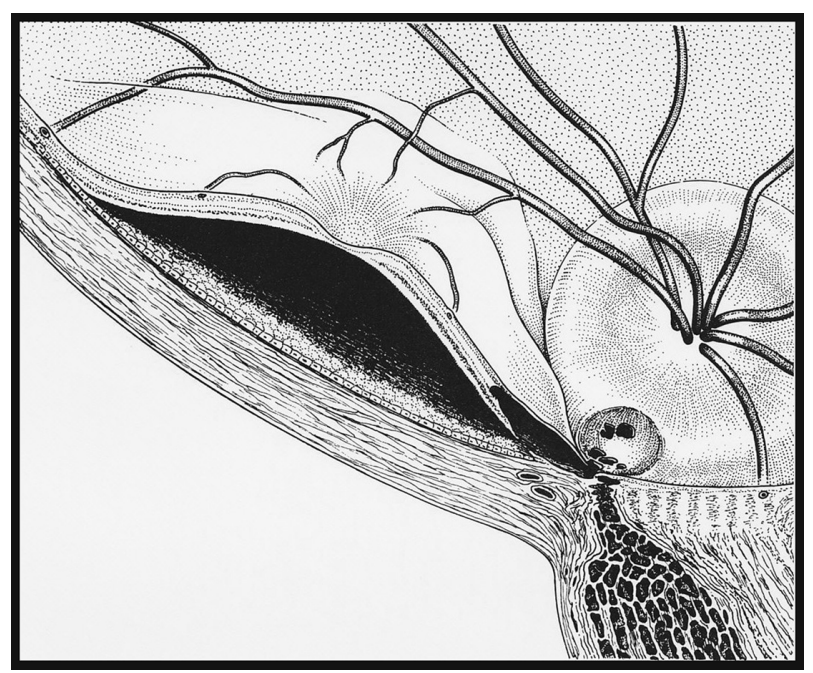

Figure 4 Artist's depiction of our specimen showing the communication between the vitreous cavity to the subretinal space.

The presence of a thin membrane spanning the optic nerve pit has previously been described. ${ }^{16,21,22}$ Doyle et al, utilizing high resolution OCT, described the characteristics of these membranes. ${ }^{17}$ These membranes were found to originate from the edges of the optic nerve cup and to follow the concave contour of the pit. Using OCT, a hyporeflective separation was visualized between the base of the pit and the membrane, with fine trabecula spanning vertically from the roof to the floor of the pit. In a histological study using LM of seven cases with optic disc pit, Ferry described a membrane of glial tissue following the pit, but the author does not detect any defects in its structure. ${ }^{10}$ Previous reports by Brockhurst ${ }^{23}$ and Bonnet ${ }^{8}$ reported the presence of holes in the roof of the optic disc pit. Small hyporeflective defects have been visualized utilizing OCT. ${ }^{24}$ In our specimen under SEM, Figure 2A and $\mathrm{B}$ clearly shows defects in the membrane overlying the optic nerve pit. At increased magnification (Figure 2B), the base of the pit can be seen through the membranous defects. Notably, the holes in the roof of the pit appear to be most numerous at its temporal margin. Overlying vitreous bands with resultant traction to this membrane have been reported by OCT; however, this finding was inconsistent. ${ }^{25}$ We did not observe any vitreous bands or vitreous traction to the overlying membranous defects in our histological specimen.

We believe that the membranous defects visualized on SEM provide access for vitreous fluid into the adjacent neurosensory retina. It has previously been suggested that the presence of an intact membrane spanning the optic nerve pit is protective against maculopathy, whereas patients with defects or collapsed membranes as visualized on OCT may have an associated serous macular detachment. ${ }^{17}$ Multiple published reports show evidence of a functional pathway between these diaphanous membrane defects and the subretinal

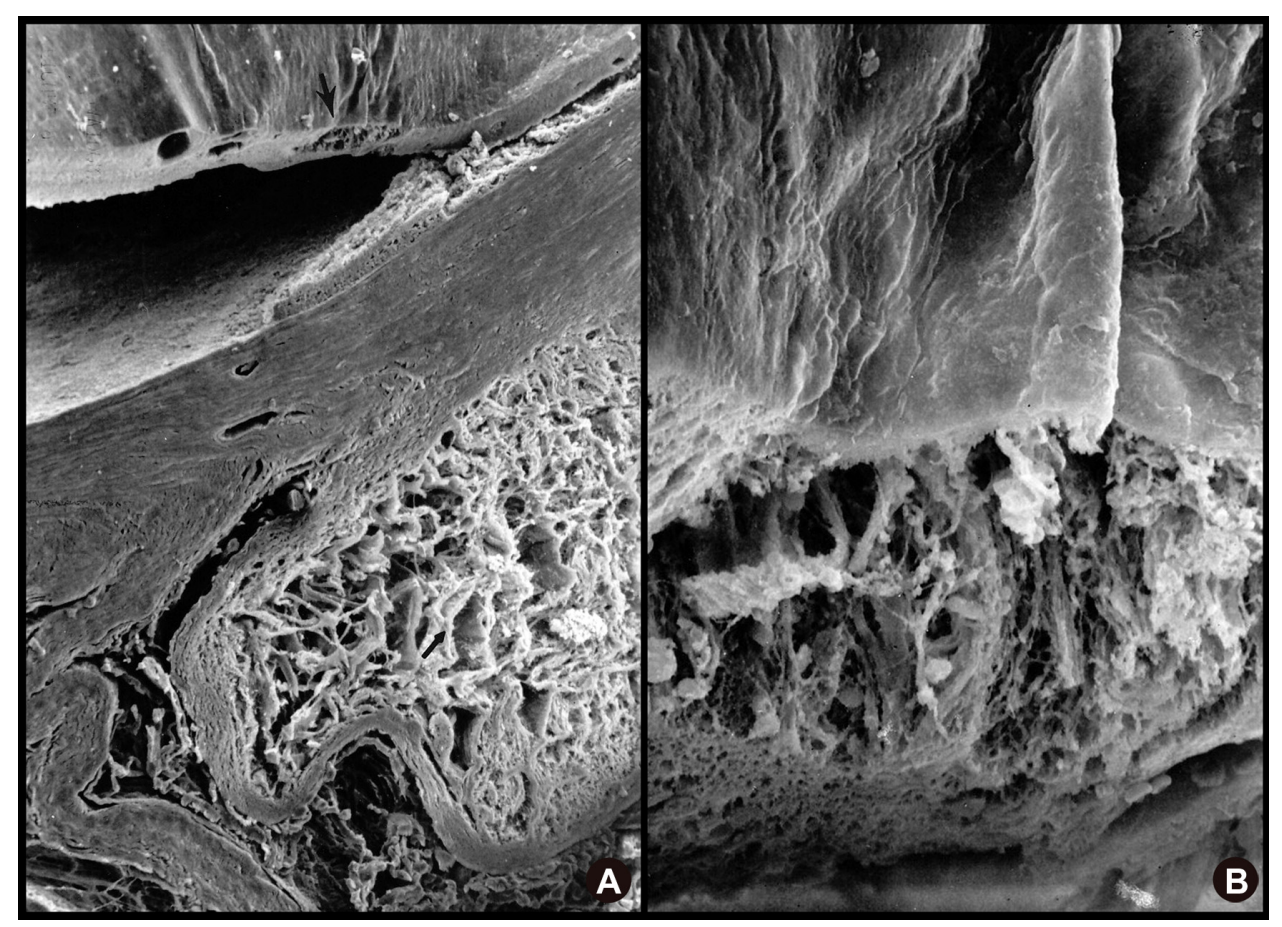

Figure 5 SEM showing extensive cavernous atrophy of the optic nerve. (A) SEM showing extensive cavernous atrophy of the optic nerve with an intact subarachnoid space. (B) higher magnification SEM of cavernous atrophy of the optic nerve with a wall of intact glial tissue surrounding this area (upper portion of image). Abbreviation: SEM, scanning electron microscope. 
space. Bonnet described a case where intravitreal gas was visualized traversing these defects overlying the optic pit into the subretinal space following macular gas tamponade. ${ }^{8}$ Johnson and Johnson ${ }^{21}$ and Postel et a ${ }^{122}$ described successful drainage of subretinal fluid through the membranous defects overlying the pit.

The origin of subretinal fluid associated with the optic nerve pit continues to be a source of controversy. It should be noted that despite cavernous atrophy of our specimen's optic nerve, the subarachnoid space had an intact meningeal sheath, and no connection to the pit or the subretinal space was visualized. In 1979, Brown et al postulated that liquid vitreous was the source of the subretinal fluid. ${ }^{26}$ After injecting India ink into the vitreous of a collie dog with an optic pit, they observed the ink flowing through the pit into the subretinal space. Kuhn et al reported a case of intracranial migration of silicon oil from a post-vitrectomized eye with optic disc split maculopathy. ${ }^{27}$ The authors demonstrated that in some cases, a direct pathway between the vitreous and the subarachnoid space may exist. Further evidence of a vitreous source of the fluid lies in the promising results of vitrectomy and gas tamponade. ${ }^{8,28}$

As stated previously, an internal schisis-like cavity develops adjacent to the optic nerve pit in eyes with associated maculopathy. Our specimen demonstrates two areas of separation within the retina. First, there is inner retinal atrophy that has progressed to a schisis (Figure $3 \mathrm{~A}-\mathrm{C}$ and Figure 5B). Multiple OCT studies have reported this common finding. ${ }^{10-18}$ Serial sections through this schisis cavity reveal a connection between the inner layer schisis cavity and outer layer detachment (Figure 3C and D). Although the presence of artifactual retinal detachment in this histological slide cannot be completely excluded, subretinal debris can be seen clearly in Figure 3D, presumably representing degenerated portions of photoreceptor outer segments. Furthermore, the patient had a known clinical history of a serous macular detachment associated with the optic nerve pit.

To our knowledge, this is the first histological specimen to demonstrate the presence of a lamellar hole connecting these two cavities. The presence of a lamellar hole was visualized stereoscopically by Lincoff et $\mathrm{al}^{20}$ and has recently been well visualized with OCT. ${ }^{15,18}$ It should be noted that a lamellar hole is not a prerequisite for fluid to gain access to the submacular space. In a series of 16 eyes with optic disc pits studied with high-resolution OCT, Imamura et al reported that a lamellar hole may not be necessary for the associated maculopathy. Although lamellar holes were visualized in some patients, in other cases fluid from the optic pit may gain direct access to all layers of the retina resulting in diffuse retinal edema similar to that found in retinal vein occlusions. ${ }^{15}$ Certainly in cases where a lamellar hole exists, the mechanism proposed by Lincoff is validated. In another study investigating the mechanism of macular detachment associated with optic nerve pit, Theodossiadis and Theodossiadis show that in the architectural distortion following macular buckling, subretinal fluid resolves only after resolution of the schisis cavity and likely centripetal displacement of an adjacent lamellar hole. ${ }^{14}$ At least in our specimen's case, it is likely that this lamellar hole provided access for fluid to pass from the inner layer schisis to the subretinal space.

In conclusion, our histopathologic analysis of a postmortem human eye with optic disc pit-associated maculopathy provides support that syneretic vitreous fluid gains access to the subretinal space. The presence of defects in the diaphanous membrane overlying the pit seen with SEM may provide access for vitreous fluid to enter into the adjacent neurosensory retina. The lamellar connection that is seen between the area of retinoschisis and the subretinal space may provide the avenue for liquefied vitreous to gain access into the subretinal space.

\section{Acknowledgements}

We would like to thank Torrence Makley, MD for his guidance during several discussions of our histopathologic case.

\section{Disclosure}

None of the authors have any financial disclosures or conflicts of interest that pertain to the information presented in this manuscript.

\section{References}

1. Wiethe T. Ein FaIl von Angeborener Difformitat der Schnervenpapille. Arch F Augenheilkd. 1882;11:14-19.

2. Brown GC, Shields JA, Goldberg RE. Congenital pits of the optic nerve head: II. Clinical studies in humans. Ophthalmology. 1980; 87(1):51-65.

3. Reed, D. Congenital pits of the optic nerve 1999. Clin Eye Vis Care. 11(2):75-80.

4. Reis W. Ein wenig bekannte typische Missbildung am Sehnerveneintritt, Z. Augenheilk. 1908;19:505-528.

5. Brown GC, Tasman WS. Congenital Anomalies of the Optic Disc. New York, NY: Grune and Stratton; 1983:97-126.

6. Petersen HP. Pits or crater-like holes in the optic disc. Acta Opthalmol. 1958;36(3):435-443.

7. Kranenburg EW. Crater-like holes in the optic disc and central serous retinopathy. Arch Ophthalmol. 1960;64:912-924.

8. Bonnet M. Serous macular detachment associated with optic nerve pits. Graefes Arch Clin Exp Ophthalmol. 1991;229(6):526-532.

9. Greear JN. Pits, or crater-like holes, in the optic disc. Arch Ophthalmol. $1942 ; 28: 467-483$. 
10. Ferry AP. Macular detachment associated with congenital pit of the optic nerve head. Pathologic findings in two cases simulating malignant melanoma of the choroid. Arch Ophthalmol. 1963;70:346-357.

11. Krivoy D, Gentile R, Liebmann JM, et al. Imaging congenital optic disc pits and associated maculopathy using optical coherence tomography. Arch Ophthalmol. 1996;114(2):165-170.

12. Rutledge BK, Puliafito CA, Duker JS, Hee MR, Cox MS. Optical coherence tomography of macular lesions associated with optic nerve head pits. Ophthalmology. 1996;103(7):1047-1053.

13. Lincoff H, Kreissig I. Optical coherence tomography of pneumatic displacement of optic disc pit maculopathy. Br J Ophthalmol. 1998;82(4): 367-372.

14. Theodossiadis GP, Theodossiadis PG. Optical coherence tomography in optic disk pit maculopathy treated by the macular buckling procedure. Am J Ophthalmol. Aug 2001;132(2):184-190.

15. Imamura Y, Zweifel SA, Fujiwara T, Freund KB, Spaide RF. High-resolution optical coherence tomography findings in optic pit maculopathy. Retina. 2010;30(7):1104-1112.

16. Karacorlu S, Karacorlu M, Ozdemir H, Burumcek E, Esgin H. Optical coherence tomography in optic pit maculopathy. Int Ophthalmol. 2007; 27(5):293-297.

17. Doyle E, Trivedi D, Good P, Scott RA, Kirkby GR. High-resolution optical coherence tomography demonstration of membranes spanning optic disc pits and colobomas. Br J Ophthalmol. 2009;93(3):360-365.

18. Vedantham V, Ramasamy K. Spontaneous improvement of serous maculopathy associated with congenital optic disc pit: an OCT study. Eye (Lond). 2005;19(5):596-599.

19. Meirelles RL, Aggio FB, Costa RA, Farah ME. STRATUS optical coherence tomography in unilateral colobomatous excavation of the optic disc and secondary retinoschisis. Graefes Arch Clin Exp Ophthalmol. 2005;243(1):76-81.
20. Lincoff H, Lopez R, Kreissig I, Yannuzzi L, Cox M, Burton T. Retinoschisis associated with optic nerve pits. Arch Ophthalmol. 1988; 106(1):61-67.

21. Johnson TM, Johnson MW. Pathogenic implications of subretinal gas migration through pits and atypical colobomas of the optic nerve. Arch Ophthalmol. 2004;122(12):1793-1800.

22. Postel EA, Pulido JS, McNamara JA, Johnson MW. The etiology and treatment of macular detachment associated with optic nerve pits and related anomalies. Trans Am Ophthalmol Soc. 1998;96:73-88.

23. Brockhurst RJ. Optic pits and posterior retinal detachment. Trans Am Ophthalmol Soc. 1975;73:264-291.

24. Hirakata A, Hida T, Ogasawara A, Iizuka N. Multilayered retinoschisis associated with optic disc pit. Jpn J Ophthalmol. 2005;49(5): 414-416.

25. Theodossiadis PG, Grigoropoulos VG, Emfietzoglou J, Theodossiadis GP. Vitreous findings in optic disc pit maculopathy based on optical coherence tomography. Graefes Arch Clin Exp Ophthalmol. 2007; 245(9):1311-1318.

26. Brown GC, Shields JA, Patty BE, Goldberg RE. Congenital pits of the optic nerve head: I. Experimental studies in collie dogs. Arch Ophthalmol. 1979;97(7):1341-1344.

27. Kuhn F, Kover F, Szabo I, Mester V. Intracranial migration of silicone oil from an eye with optic pit. Graefes Arch Clin Exp Ophthalmol. 2006; 244(10):1360-1362.

28. Cox MS, Witherspoon CD, Morris RE, Flynn HW. Evolving techniques in the treatment of macular detachment caused by optic nerve pits. Ophthalmology. 1988;95(7):889-896.
Clinical Ophthalmology

\section{Publish your work in this journal}

Clinical Ophthalmology is an international, peer-reviewed journal covering all subspecialties within ophthalmology. Key topics include: Optometry; Visual science; Pharmacology and drug therapy in eye diseases; Basic Sciences; Primary and Secondary eye care; Patient Safety and Quality of Care Improvements. This journal is indexed on

\section{Dovepress}

PubMed Central and CAS, and is the official journal of The Society of Clinical Ophthalmology (SCO). The manuscript management system is completely online and includes a very quick and fair peer-review system, which is all easy to use. Visit http://www.dovepress.com/ testimonials.php to read real quotes from published authors. 